\title{
Using the Hitachi SEM to engage learners and promote next generation science standards inquiry
}

D. Menshew

D. E. Menshew, "Using the Hitachi SEM to engage learners and promote next generation science standards inquiry," Proc. SPIE 9236, Scanning Microscopies 2014, 92360M (16 September 2014); doi: 10.1117/12.2066385

SPIE Event: SPIE Scanning Microscopies, 2014, Monterey, California, United States 


\title{
Using the Hitachi SEM to engage learners and promote Next Generation Science Standards Inquiry.
}

\author{
D. E. Menshew*, James C. Enochs High School 3201 Sylvan Ave. Modesto, CA 95355
}

\begin{abstract}
Keywords: Hitachi, TM3000, STEM, SEM, NGSS, Enochs High, forensics, Ohlone College; salmonids

In this study participants will learn how the Hitachi TM3000 scanning electron microscope (SEM) played a central role in one school's movement towards Next Generation Science Standards (NGSS) and promoted exceptional student engagement. The device was used to create high quality images that were used by students in a variety of lab activities including a simulated crime scene investigation focusing on developing evidence based arguments as well as a real world conservation biology study. It provided opportunities for small group and independent investigations in support of NGSS, and peer-peer mentoring. Furthermore, use of the device was documented and were included to enhance secondary students' college and scholarship applications, all of which were successful.
\end{abstract}

\section{INTRODUCTION}

During the 2011-2012 academic year, staff members of James C. Enochs High School in Modesto, CA became aware of the Hitachi Corporation's support of enhanced science learning through a previously established relationship with the Ohlone College's LAB consortium. Teachers were invited to attend training to introduce the TM 3000 and promote its use in the secondary classroom with receptive, advanced programs. Following the workshop, a follow-up session was scheduled to take place in the summer of 2012. During this event, the Hitachi Corporation arranged to deliver the device to the Enochs High School campus, with two expert representatives in attendance to train students and offer suggestions on its use to perform investigations.

The delivery of the TM3000 drew considerable stakeholder interest. Members of law enforcement, a nearby community college professor, other teachers and a small group of students spent several hours learning how to use the device. Local media attended as well. Students worked in teams to design a mock crime mystery to be solved by their peers during the following school year. Arrangements were made with Hitachi Corporation to deliver the device the following spring. This was done in the spring of 2013 and the device was on the Enochs campus for nine days. Student engagement was high, and the device attracted the attention of a wide variety of learners across gender and ethnic groups in the school's program.

During the following academic year, representatives of the Hitachi Corporation. contacted the Enochs staff and offered to extend the use of the device to three weeks. This opportunity was gladly accepted and plans were made to include the TM3000 in a newly instituted salmonids program operated under the guidance of the California Department of Fish and Wildlife $(\mathrm{CDF} \& \mathrm{~W})$. Enochs staff attended training and became certified to raise Chinook salmon in the classroom. The device was used to support this effort through water quality studies made by the students. Data from the salmonids program was included in the end of project report to the CDF\&W.

The TM3000 has served as an important part of the Enochs High Forensic Biotechnology Programs advanced offerings and has been an important part of showcasing the ability of the program to offer novel learning opportunities to a region that lacks the kinds of support found in the nearby California Bay Area. Furthermore, it has been a major dispositive factor in the applications of numerous students' college, university, and scholarship applications. The success of many of these has demonstrated how use of this device can serve to differentiate the college and/or scholarship application of a motivated and well supported student from their peers when seeking to continue post-secondary STEM education.

*menshew.d@monet.k12.ca.us phone 1 209-550-5500; fax 1 209-550-3413

Scanning Microscopies 2014, edited by Michael T. Postek, Dale E. Newbury, S. Frank Platek, Tim K. Maugel, Proc. of SPIE Vol. 9236, 92360M - (C) 2014 SPIE · CCC code: 0277-786X/14/\$18 - doi: 10.1117/12.2066385 


\section{METHODOLOGY}

The experience and results obtained from the partnership between Enochs High and the Hitachi Corporation is a positive example of the power of vertical networking and articulation, corporate social responsibility, and the efforts of dedicated students and teachers. Hitachi Corporation's management, seeing the decline in U.S. students pursuing science, technology, engineering and math (STEM) careers led to the establishment of the Hitachi High-Technology initiative. According to According to the Engineering Workforce Commission report of 2005, over the past 20 years, U.S. students who achieved bachelor's degrees in engineering declined by 19.8\%. Recent Programme for International Student Assessment (PISA) scores show similar disappointing numbers. For example, a report from 2012 showed that U.S. Students teenagers in the U.S. slipped from 25th to 31st in math since 2009; from 20th to 24th in science; and from 11th to 21 st in reading, (Weisenthal 2013). Realizing the need to support science education at multiple levels, Ohlone College agreed to partner with Hitachi Corporation to make the TM3000 scanning electron microscope available to teachers in the San Francisco Bay Area and beyond.

Using their extensive network of biotechnology educators as a base, Ohlone staff were able to assemble a cohort of more than a dozen interested teachers at the first Saturday TM3000 training. The learning curve proved to be short as educators viewed a presentation and demonstration by Hitachi Corporation staff. They were invited to experience the device for themselves. Post training discussions revealed a strong and unanimous interest by the attendees to engage their students through the use of the device.

Enochs High staff, now qualified to teach using the TM3000 made arrangements to have the device delivered to the school during the following summer of 2012 so that a core group of students could be introduced to the device. Hitachi Corporation also provided two SEM experts to train the students and additional teachers. The event attracted the attention of the local medial leading to a very favorable article in the Modesto Bee newspaper (Austin 2012). Eight students attended the entire day long training. During this time they learned how to initiate the device, prepare samples for imaging, then to record their images in the school's new TM3000 image library. The students were given a design challenge to develop a storyline based on a mystery that would be solved by their peers during the following school year. While some students were working with the Hitachi Corporation's SEM experts, others worked on the storyline, logistics and PowerPoint to be used in the lesson.

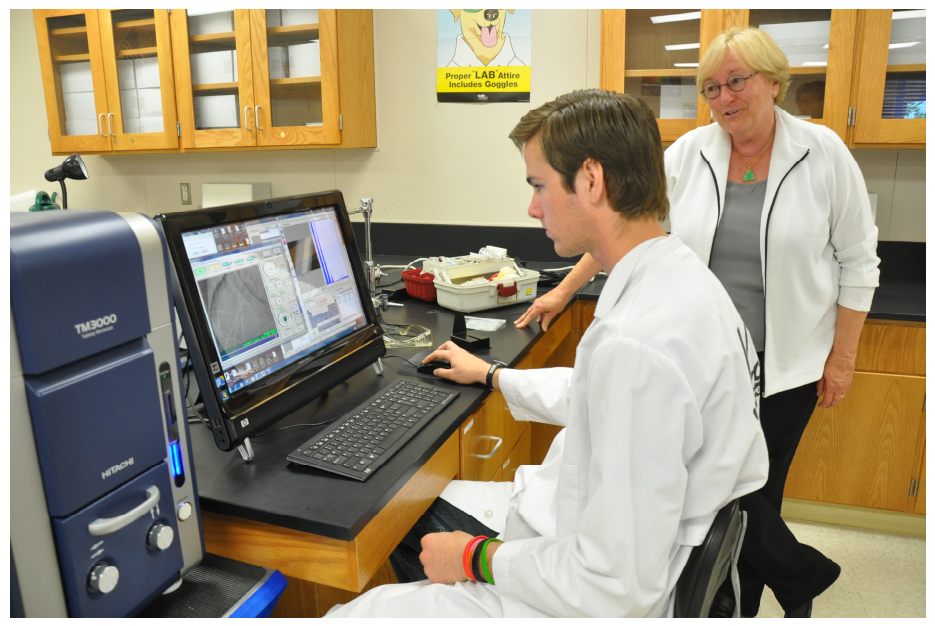

Figure 1. Student works with Hitachi trainer.

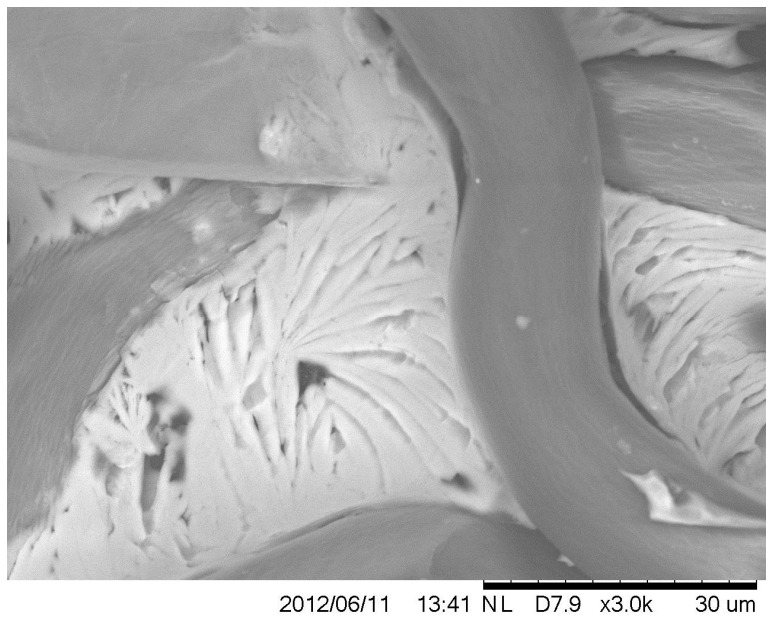

Figure 2. SEM of almond fiber with CuSO4.

Students decided that the scenario would be one of a crime having been committed in a nearby orchard. As Modesto is in an agricultural area, this provided connection to prior knowledge. They decided that a suspect was to have been taken into custody. The TM3000 images were to be used to determine if substances found on the suspect's clothing were in keeping with where the suspect claimed to be on questions by authorities. A number of options were created by the 
student team. One version used almond hull fibers contaminated with a copper sulfate which may have been used in the California's Central Valley on almond trees. (See figure 2). This ran counter to the suspect's claim that he had never been anywhere near an almond orchard but was at the beach when the crime occurred. This ran counter the absence of beach sand particles on both his person and in his vehicle.

Students reported a short learning curve, and observers confirmed that the learners connected well with the device and were well engaged in the learning. The most telling indicator was the observation that the students, some who often chafe at a 44 minute class period during the regular school year, were in attendance in the summer and worked for several hours to learn the device and complete the lesson design challenge.

The following spring, the device returned to Enochs High School and was showcased for a much wider audience. The summer design team became the peer trainers. Staff observed highly positive peer to peer interaction. Great care was taken by the students with the TM3000, buy-in to the lesson was in evidence by the sense of ownership seen in the trainers that transferred to many of the larger classes. Special arrangements were made to offer use of the device before at 6:00 am, during lunch periods and after school. It was estimated by staff that more than $35 \%$ of these learning opportunities saw one or more students in attendance. The device attracted both genders and a variety of ethnicities.

During the use of the investigation that was designed in the summer of 2012, the first cohort of students who had designed the lesson was called on to lend their guidance during class time. Enochs teaching staff reported that the trainers being given the opportunity to act as well trained experts in the use of such an advanced and high value device improved these students' self-esteem and self-confidence as well as overall view of science as a pursuit. While during this time staff has no specific metrics on this, it has been noted that the same students who came forward to work with the device have also volunteered to attend a number of other science related extra-curricular activities. While it cannot be said whether or not this would have happened without the presence of the TM3000, or if the device promoted their additional involvement, it certainly supported their engagement in a positive manner and didn't leave them feeling that they couldn't do science. The impression of the teaching staff was that the involvement and visitations by a wide variety of notable supporters enhanced the overall value of the student's experience. Designing metrics for these assumptions would be a worthy extension of this project in future studies.

The envisioned role of the TM3000 was to engage learners and set high expectations for the role of technology in the students' learning. Acting as one component in a technology rich program, the device allowed the site and district to continue to make novel learning opportunities to our population. This approach has been the basis for the growth of our program and the exceptional testing scores that we have seen over the past three years. The TM3000, as a showpiece and an engagement tool allows the program to attract and motivate students and gives staff the opportunity to offer learning opportunities in a region that suffers from numerous negative indicators including high unemployment. For example, Enochs High School is situated in Stanislaus County. During the 2009 year, unemployment reached 16.9\% for that county according to the U. S. Bureau of Statistics. (Stanislaus County Unemployment Rate 214)

During the three year period in which the TM3000 has been a part of our annual offerings there has been a major change in the direction of science education. The State of California Dept. of Education has ended the California Testing and Reporting (STAR) examination where the Hitachi TM3000 device use supported the Investigation and Experimentation standards. California students will now be moving to the new NGSS which is grounded in research which indicates that if the U.S. is to be competitive in a global economy, the development of certain habits of mind along with core knowledge are critical. The use of the device allows for multiple facets of NGSS to be addressed both simultaneously and sequentially. For example when students were working with the fibers in the aforementioned crime scene scenario, they were challenged to explain why almonds had them. They realized that form follows function, and then were quizzed to explain where this trait came from (genes in the plant). The TM3000 allowed for a number of excellent teachable moments. As the device was used to create authentic images that would be consistent with actual forensic investigations, students would be satisfying the NGSS standards that speak to supporting arguments with evidence.

The Hitachi TM 3000 tabletop scanning electron microscope provided an easy to use platform for high quality, meaningful student engagement. Staff was well trained by Hitachi Corporation representatives and was well qualified to 
deliver core concept science instruction with the device. After delivery, students were encouraged to take advantage of numerous lab hours, starting as early as 5:30 AM and included some afternoons, evenings and Saturday's. It was found that the Hitachi TM3000 appealed across genders and ethnicities and gave a variety of students the chance to explore an otherwise unseen world.

Another benefit from the use of the device in our classroom was the beginning-to-end method of investigation. This supports the approach of NGSS. Students were encouraged to develop their own hypotheses and then find samples that they could prepare, load into the device and photograph. Social media was engaged when pictures were posted online of students presenting their findings on the device. The teacher then used images in classroom teaching to further engage learners in analysis and discussions.

Before pickup, the Hitachi TM3000 was used in a cooperative investigation by our most qualified student and a pathologist with the California Dept. of Fish and Wildlife. The student drew samples from three tanks in which a total of 180 salmon were being raised for local river release. He then prepared these along with river water for viewing with the device to judge observable differences. When a mortality issue developed, the student was directed by the pathologist examine one of the eggs in the tank for parasites. Communication between the student and the pathologist gave the learner the experience of doing authentic science. Confirmation that there were no parasites in the sample, and that the death of the egg was attributable to other causes became a rich source of discussion and further engaged the students, acting to motivate them for fear that they lose more fish.

\section{RESULTS}

Results from the use of the device are varied. First would be the number of students engaged with the device. In the initial summer session described above, eight students were trained to the level of being able to produce high quality images suitable for use in investigations. This small group went on to train $6711^{\text {th }}$ grade peers the following school year and $3312^{\text {th }}$ grade students. The following year this number rose to $7211^{\text {th }}$ graders and $3912^{\text {th }}$ graders.

As mentioned earlier, the Hitachi TM3000 has acted over three years as part of a larger learning experience to attract and motivate learners. Much as a pencil can allow a student to produce a high quality essay that allows them to grow internally and set the foundation for future achievements, the device acts to support a broader technology rich program.

Staff believes that the device has been an important part of the overall pattern in measureable student achieve for reasons stated above.

In Figure 3 the California State Testing and Reporting scores are presented for years 2010-2013. It can be seen that those students in the Forensic Biotechnology Program outperform both non program students both on campus and within district. The number of students who are advanced is far beyond comparable groups.

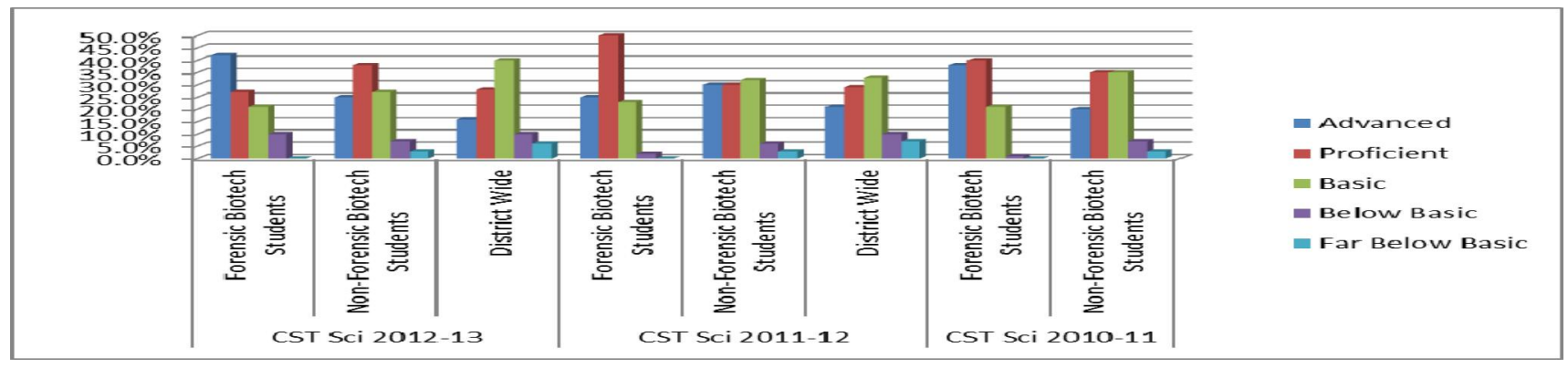

Figure 3 Comparison of California State English Language Arts testing results 2010-2013 inclusive. (Pendley 2014)

It can also be seen that the number of students who perform at below and far below basic are lower than site and district students. It can also be seen that there is an increase in the number of students with advanced scores year over year while the number of far below basic is minimal. 


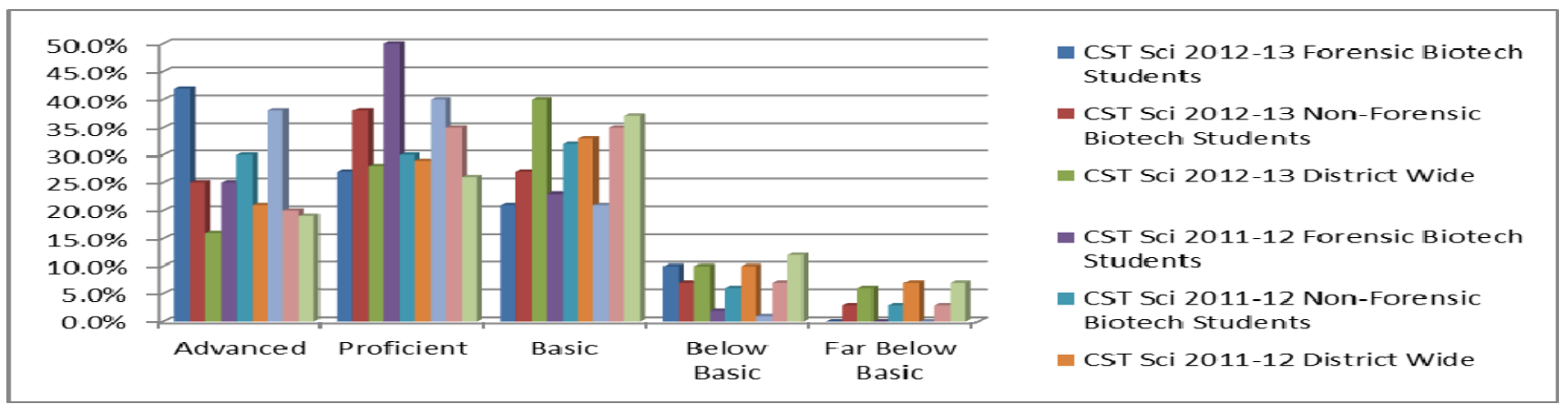

Figure 4 Comparison of CST Science Scores with program, same site non program and district students. (Pendley 2014)

In figure 4 the CST science scores show positive results, with increases in advanced and proficient.

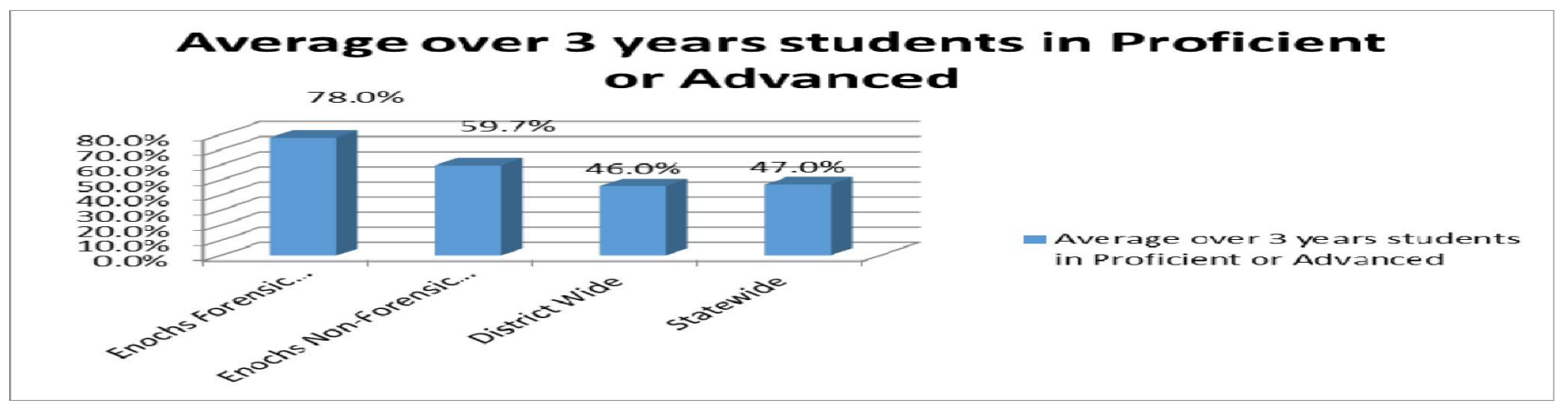

Figure 5 Comparison of program students achieving advanced and proficient in CST for English Language Arts vs. same site non program, district and statewide students. (Pendley 2014)

In figure 5, the program students average over three years in English ELA. Program students. Program students achieved a $78 \%$ while the state average was $47 \%$ advanced or proficient.

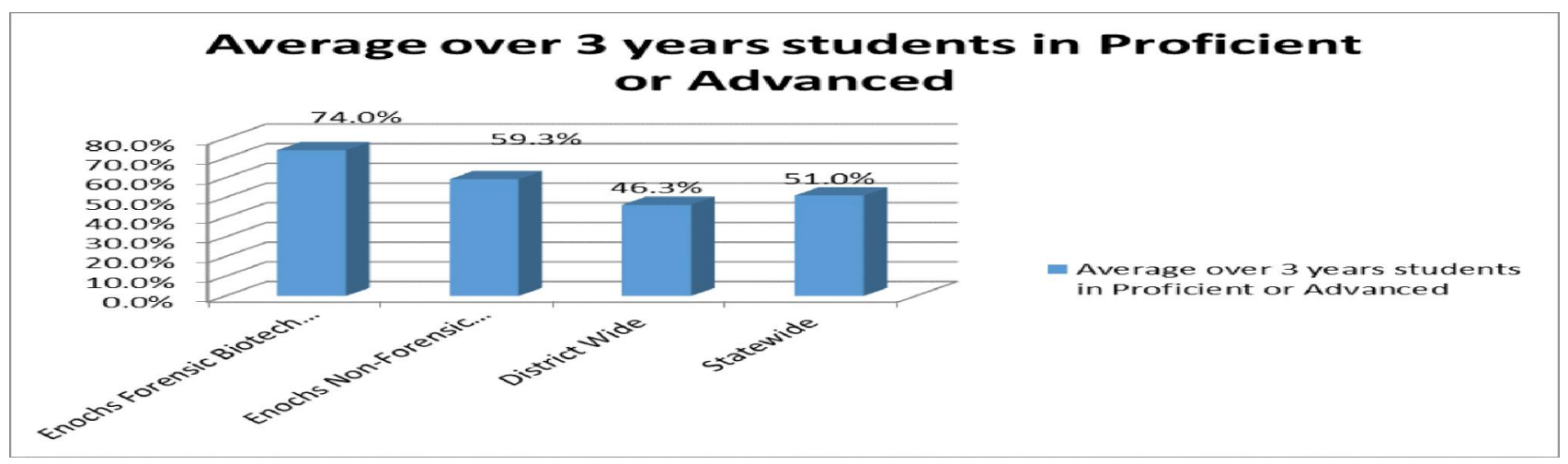

Figure 6. Comparison of program students' scores on CST for science years 2010-2013. (Pendley 2014)

In figure 6 the trend that is seen in figures 1-5 continues, with program students outperforming site, district and state peers. Here the difference is $23 \%$ above the state students.

Specific student success data includes student A, a Hispanic female who became a trainer, logged more than 21 hours of extracurricular time on the device. She applied for and received a scholarship from a local teacher's organization.

Student B, a Caucasian male, logged more than 43 hours of extracurricular time on the device over two school years and summer. He also applied for multiple scholarships, winning two as well as entrance to UC Santa Barbara. This student 
also completed 8 years of science classes and his Eagle Scout before graduation. Student $C$ was one of the group of 8 students who attended the summer 2012 session. He applied for and was accepted to UC Santa Barbara's advanced learning program which required a letter of recommendation. His work with the TM3000 figured prominently in his letter.

\section{CONCLUSION}

Evidence that the Enochs High program effectively engages learners compares well with site, district and state statistics is presented above. We conclude that while it may be true that outstanding students are attracted to high level, rigorous and complex learning opportunities, it is also true that the TM3000 with strong support of Hitachi Corporation staff has provided some of provides those opportunities. We contend that the device supports a well-designed and forward looking high school program. It has allowed for new and renewed partnerships with interested stakeholders, and was instrumental in engaging a local community college with a national recognized electron microscope program to arrange a visitation by Enochs students. An unforeseen and positive consequence of this trip was to have had more than a dozen young ladies in attendance. With these kinds of learning opportunities, it should be no surprise that this program's approach, armed with learning tools like the TM3000 have produced the results described above. We contend that it is no coincidence that students who participated as trainers and then requested letters of recommendation, or listed on their vitae and applied for scholarships and special program inclusion were successful in their applications.

What is most notable is that the Enochs High Forensic Biotech Program as a partnership academy, is funded by the California Department of Education. As such it is required to have $51 \%$ of its student population designated as at risk. While inherently outstanding students who are often well equipped with the skills needed for success to not often fall into this category, the scores as described in this study are indicative of science learning worth taking note of.

It is our conclusion that the TM3000 serves to offer extensions of existing lessons, support for NGSS, opportunities for engagement with a wide variety of learners, and highlights the advanced nature of the Forensic Biotechnology Program at Enochs High school. Experiences with the device, well supported by the Hitachi Corporation will continue to be an important part of learning in this technology rich partnership academy.

\section{NEXT STEPS}

The use of the TM3000 has been a highly fruitful learning experience for both the Enochs staff and students. If the device continues to be brought to the campus, more formalized application to the NGSS will be a top priority. Second, measures will be developed to measure the devices' impact and attempt to separate that from the overall program's effect. This would allow for a more thoughtful study of the value of the experience and would enable staff to tailor the lessons accordingly.

Staff would like to make a stronger effort to engage exceptional and other students within district by approaching the Gifted and Talented Education coordinator. An appeal would be made to solicit all teachers district wide to look for students whom they think would benefit from a visit with our team of student experts. Scheduling and engagement would follow. Perhaps the device would become a recruitment tool for the program. 


\section{REFERENCES}

Austin, Nan (June 21, 2012) Enochs students get high-tech help for 'CSI: Modesto' Retrieved from http://www.tmcnet.com/usubmit/2012/06/21/6386830.htm July 18, 2014

Pendley, Derick (March, 2014) Statistics prepared for annual California Partnership Academy report, Modesto, CA.

Stanislaus County Unemployment Rate (July 18, 2014) Retrieved from https://www.google.com/\#q=stanislaus\%20 county\%20unemployment $\% 20$ statistics

Weisenthal, Joe (December 3, 2013) Here's The New Ranking Of Top Countries In Reading, Science, And Math

Retrieved from http://www.businessinsider.com/pisa-rankings-2013-12\#ixzz37tPUeUQX 